\title{
A novel chalcone-based molecule, BDP inhibits MDA-MB-231 triple-negative breast cancer cell growth by suppressing Hsp90 function
}

\author{
YONG JIN OH and YOUNG HO SEO \\ College of Pharmacy, Keimyung University, Daegu 704-701, Republic of Korea
}

Received April 28, 2017; Accepted August 14, 2017

DOI: $10.3892 /$ or.2017.5925

\begin{abstract}
Triple-negative breast cancer (TNBC) is a molecularly diverse and heterogeneous disease and the molecular heterogeneity of TNBC increases the difficulty in improving survival rates. To date, therapeutic approaches for the treatment of TNBC such as hormonal chemotherapy and trastuzumabbased therapy have been limited by the lack of target receptors such as estrogen receptor (ER), progesterone receptor (PR), and human epidermal growth factor receptor 2 (Her2), emphasizing the urgent need for identifying new therapeutic options. In this regard, heat shock protein 90 (Hsp90) has emerged as an attractive therapeutic target for TNBC. Hsp90 plays a central role in regulating correct folding, stability, and function of numerous oncogenic proteins. In the present study, we evaluated the in vitro effect of a small molecule Hsp90 inhibitor, (E)-3-(2-bromo-3,4,5-trimethoxyphenyl)-1(2,4-dihydroxyphenyl)prop-2-en-1-one (BDP) on TNBC cell line, MDA-MB-231. This study indicated that BDP efficiently inhibited the growth of MDA-MB-231 cells in a dose- and time-dependent manner. BDP induced overall degradation of multiple oncogenic proteins including EGFR, Her2, Met, Akt, c-Raf, and Cdk4, consequently leading to apoptotic cell death. The flow cytometric analysis revealed that BDP promoted cell cycle arrest at $\mathrm{G}_{2} / \mathrm{M}$ phases. Moreover, BDP treatment attenuated the migration of MDA-MB-231 cells and impaired MMP9 activity, which are essential processes for tumor metastasis. Collectively, BDP represents a new class of Hsp90 inhibitor and shows therapeutic potential for TNBC treatment.
\end{abstract}

\section{Introduction}

Triple-negative breast cancers (TNBCs), which are characterized by the lack of estrogen receptor (ER), progesterone receptor (PR), and human epidermal growth factor receptor (Her2), account for $15-20 \%$ of all breast cancers (1). These

Correspondence to: Professor Young Ho Seo, College of Pharmacy, Keimyung University, Daegu 704-701, Republic of Korea

E-mail: seoyho@kmu.ac.kr

Key words: triple-negative breast cancer, Hsp90, breast cancers, chalcone, small molecule cancers exhibit a more aggressive phenotype and a poorer clinical outcome compared to other breast cancer subtypes, and that is because of the high propensity for metastatic progression and the absence of specific targeted treatment options (2,3). Besides, the molecular heterogeneity of TNBC increases the difficulty in improving survival rates and developing specific targeted therapy.

Due to the lack of ER, PR, and Her2 receptors, patients with TNBC could not benefit from hormonal and trastuzumabbased targeted therapies and thus conventional chemotherapy such as taxanes and anthracyclines remains the mainstay for the treatment of TNBC (4). Although a significant number of TNBC patients respond well to the conventional chemotherapy, the prognosis of TNBC patients remains poor and alternative therapeutic approaches are therefore highly needed.

Heat shock proteins 90 (Hsp90) is an adenosine triphosphate (ATP) dependent molecular chaperone protein, which is widely expressed in breast cancers (5-7). Hsp90 plays a critical role in the correct folding, stability, and function of its substrate proteins, referred to as 'client proteins' (8-10). These client proteins include epidermal growth factor receptor (EGFR/ErbB1), human epidermal growth factor receptor 2 (Her2/ErbB2), mesenchymal-epithelial transition factor (Met), anaplastic lymphoma kinase (Alk), protein kinase B (Akt/PKB), cellular rapidly accelerated fibrosarcoma (c-Raf), cyclin-dependent kinase $4(\mathrm{Cdk} 4)$, hypoxia-inducible factor 1 (Hif-1 $\alpha$ ), matrix metalloproteinase 2 (MMP2) (11-14). Hsp90 has received significant attention and emerged as an attractive target for cancer therapy, in that the inhibition of single Hsp90 protein induces client protein degradation via the ubiquitinproteasome pathway, and subsequently results in simultaneous blockage of multiple signaling pathways in the heterogeneous cancers.

Chalcones represent an important group of naturally occurring molecules, which are especially abundant in edible plants such as green tea, licorice, and bean sprouts. Chemically, chalcones are aromatic ketone with two phenyl linked by three-carbon enone moiety (Fig. 1). Chalcones exhibit a wide spectrum of biological activities including anti-oxidative (15), anti-inflammatory (16), and anticancer activities (17-21). More importantly, chalcones have been shown to interfere with each step of carcinogenesis including initiation, promotion and progression, suggesting that chalcones and their derivatives could serve as promising candidates for anticancer drugs. 
In our ongoing effort to develop a new Hsp90 inhibitor (22-26), we have recently found that a chalcone-based small molecule (E)-3-(2-bromo-3,4,5-trimethoxyphenyl)-1-(2,4-dihydroxyphenyl)prop-2-en-1-one (BDP) impairs the growth of cancer cells and this observation prompted us to direct our efforts toward investigating its biological activities and the underlying mechanisms of action.

\section{Materials and methods}

Cell culture and material. Triple-negative breast cancer cells MDA-MB-231 were grown in DMEM high glucose, supplemented with streptomycin $(500 \mathrm{mg} / \mathrm{ml})$, penicillin (100 U/ml), and $10 \%$ fetal bovine serum (FBS). Cells were grown to confluence at $37^{\circ} \mathrm{C}$ in humidified atmosphere with $5 \% \mathrm{CO}_{2}$. BDP was prepared following the previously reported procedure (26). For in vitro studies, BDP and geldanamycin (Alexis Biochemical, Farmingdale, NY, USA) were dissolved in DMSO. Antibodies for EGFR, Her2, Met, Akt, c-Raf, Cdk4, Hsp90, Hsp70, PARP, caspase 3, cleaved caspase 8, Bax and $\beta$-actin were purchased from Cell Signaling Technology (Beverly, MA, USA). Anti-Bcl-2, anti-mouse, and anti-rabbit antibodies were purchased from Santa Cruz Biothechnolgy (Dallas, TX, USA).

Cell proliferation assay. MDA-MB-231 cells ( $2 \times 10^{3}$ cells/well) were seeded in 96-well plate, the medium volume was brought to $100 \mu \mathrm{l}$, and the cells were allowed to attach for $24 \mathrm{~h}$. The cells were then incubated with $\operatorname{BDP}(10,30,50,70$ and $100 \mu \mathrm{M})$ or $\mathrm{GA}(1 \mu \mathrm{M})$ at $37^{\circ} \mathrm{C}$ with $5 \% \mathrm{CO}_{2}$ for 1,2 and 3 days. CellTiter 96 Aqueous One Solution reagent (Promega, Madison, WI, USA) was added into each well following the manufacturer's instructions. The absorbance of each sample was determined by Tecan Infinite F200 Pro plate reader at 490 and $690 \mathrm{~nm}$ as the reference wavelength.

Assessment of cell morphology. MDA-MB-231 cells $\left(1 \times 10^{5}\right.$ cells/well) were seeded in 12-well plate, and the cells were allowed to attach for $24 \mathrm{~h}$. Culture medium was then changed to fresh complete medium containing BDP (10, 30 and $50 \mu \mathrm{M}$ ). After being incubated for $24 \mathrm{~h}$, the cell morphology was observed with inverted phase contrast microscope (Olympus, Japan) at 20x objective.

Western blotting. After being treated with BDP (10, 30, 50 and $70 \mu \mathrm{M})$ or GA $(1 \mu \mathrm{M})$ for $24 \mathrm{~h}$, MDA-MB-231 cells were harvested and lysed in ice-cold lysis buffer $(25 \mathrm{mM}$ Tris- $\mathrm{HCl}$ $\mathrm{pH} 7.6,150 \mathrm{mM} \mathrm{NaCl}, 1 \% \mathrm{NP} 40,1 \%$ sodium deoxycholate, $0.1 \%$ SDS, $1 \mathrm{mM}$ phenylmethylsulfonyl fluoride). The $30 \mu \mathrm{g}$ of lysate per lane was separated by SDS-PAGE and followed by transferring to a PVDF membrane (Bio-Rad, Hercules, CA, USA). After being blocked with 5\% skim milk in TBS with $0.1 \%$ Tween-20 (TBS-T), the membrane was incubated with the corresponding antibodies in TBS-T at $4^{\circ} \mathrm{C}$ overnight. Proteins were visualized by using enhanced chemiluminescence (ECL) reagent according to the manufacturer's instructions (GE Healthcare, Pittsburgh, PA, USA).

Reverse transcriptase-polymerase chain reaction (RT-PCR). RT-PCR was performed using the RT-PCR kit (Bio-Rad) following the manufacturer's protocol. Briefly, total RNA was extracted from cultured cells using TRIzol reagent (Fisher Scientific, Hampton, NH, USA), reverse transcribed, and then subjected to PCR. The following primers were used for the amplification of human Met, Akt and $\beta$-actin: Met, 5'-AAG AGGGCATTTTGGTTGTG-3' (forward) and 3'-GATGAT TCCCTCGGTCAGAA-5' (reverse); Akt,5'-TTTTATTTCTCG GGTGCAT-3' (forward) and 3'-CATTTCCCTACGTGAA TCGG-5' (reverse); $\beta$-actin, 5'-AGAAAATCTGGCACCAC ACC-3' (forward) and 3'-CCATCTCTTGCTCGAAGTCC-5' (reverse).

Apoptosis assay. After being treated with BDP (10, 30, 50 and $70 \mu \mathrm{M})$ or $\mathrm{GA}(1 \mu \mathrm{M})$ for $24 \mathrm{~h}, \mathrm{MDA}-\mathrm{MB}-231$ cells were resuspended in $1 \mathrm{X}$ Annexin $\mathrm{V}$ binding buffer, and stained with Annexin V for 15 min. The cells were treated with FACS buffer and propidium iodide prior to FACS analysis. Apoptotic cells were analyzed by fluorescent-activated cell sorting (FACS) flow cytometer (BD Bioscience, San Jose, CA, USA) and BD CellQuest ${ }^{\mathrm{TM}}$ Pro software.

Cell cycle arrest. For cell cycle assay, MDA-MB-231 cells were treated with $\mathrm{BDP}(10,30,50$ and $70 \mu \mathrm{M})$ or GA $(1 \mu \mathrm{M})$ for $24 \mathrm{~h}$. The cells were resuspended in $300 \mu \mathrm{l}$ of PBS, treated with $700 \mu \mathrm{l}$ of $95 \%$ ethanol, and gently vortexed. The cells were then incubated at $4^{\circ} \mathrm{C}$ for $2 \mathrm{~h}$, washed with PBS, resuspended in $500 \mu \mathrm{l}$ of PBS containing $50 \mu \mathrm{g} / \mathrm{ml}$ of propidium iodide and $1 \mu \mathrm{g} / \mathrm{ml}$ of RNAse A. After being incubated for an additional $30 \mathrm{~min}$ at room temperature in the dark, the cells were analyzed by FACS flow cytometer and BD CellQuest Pro software.

Wound healing assay. MDA-MB-231 cells ( $3 \times 10^{5}$ cells/well) were seeded in 6-well plate, and the cells were allowed to attach for $24 \mathrm{~h}$. The $80 \%$ confluent cells were wounded with a linear scratch by using disposable $200 \mu \mathrm{l}$ micropipette tip. The cells were washed with medium to remove cell debris and covered with serum-free medium containing BDP $(10 \mu \mathrm{M})$. After being incubated for $24 \mathrm{~h}$, migrated cells were determined under inverted phase contrast microscope (Olympus) at 10x objective.

Gelatin zymography assay. MDA-MB-231 cells $\left(5 \times 10^{5}\right.$ cells/dish) were seeded in $60 \mathrm{~mm}$ dish and the cells were allowed to attach for $24 \mathrm{~h}$. The cells were then washed with PBS and incubated with serum-free medium containing BDP $(10$ and $30 \mu \mathrm{M})$ or $\mathrm{GA}(1 \mu \mathrm{M})$ for $24 \mathrm{~h}$. Conditioned media from cell cultures treated with BDP or GA were collected, centrifuged, and mixed with sample buffer $(60 \mathrm{mM}$ Tris- $\mathrm{HCl}$ $\mathrm{pH} 6.8,25 \%$ glycerol, $2 \%$ SDS, $0.1 \%$ bromophenol) without reducing agents. The corresponding samples were loaded on $10 \%$ polyacrylamide gels with gelatin $(1 \mathrm{mg} / \mathrm{ml})$ and separated by gel electrophoresis. Gels were then washed with $2.5 \%$ Triton X-100 for $40 \mathrm{~min}$ and incubated in incubation buffer (50 mM Tris, $0.15 \mathrm{M} \mathrm{NaCl}, 10 \mathrm{mM} \mathrm{CaCl}_{2}, 0.05 \%$ sodium azide) at $37^{\circ} \mathrm{C}$ for $72 \mathrm{~h}$. Gels were stained with $1 \%$ coomassie staining solution containing $10 \%$ acetic acid and $20 \%$ methanol, and incubated at room temperature for $1 \mathrm{~h}$. Proteolytic activity was detected as clear band against the background stain of undigested substrate. 
<smiles>O=C(/C=C/c1ccccc1)c1ccccc1</smiles>

Chalcone<smiles>COc1cc(/C=C/C(=O)c2ccc(O)cc2O)c(Br)c(OC)c1OC</smiles>

Figure 1. Structure of a chalcone-based small molecule, BDP.

Statistical analysis. Quantitative data are presented as mean value \pm SD. The statistical significance of compared values was determined by using Student's t-test, and $\mathrm{p}<0.001, \mathrm{p}<0.01$, and $\mathrm{p}<0.05$ were considered to indicate statistically significant results.

\section{Results}

BDP has anti-proliferative effect on MDA-MB-231 cells. We first evaluated the dose- and time-dependent effect of BDP on the growth of MDA-MB-231 cells. MDA-MB-231 cells were treated with various concentrations $(0,10,30,70$ and $100 \mu \mathrm{M})$ of BDP for 1, 2 and 3 days and cell viability was determined using MTS colorimetric assay (Fig. 2A). The assay indicated that BDP afforded a potent growth-inhibitory effect on MDA-MB-231 cells in a dose- and time-dependent manner.
The treatment of cells with BDP $(30 \mu \mathrm{M})$ effectively impaired nearly $50 \%$ of MDA-MB-231 cell growth.

We also observed the morphology changes of MDA-MB-231 cells (Fig. 2B). MDA-MB-231 cells became round and floating upon the treatment of cells with 30 or $50 \mu \mathrm{M}$ of BDP for $24 \mathrm{~h}$, which indicated typical characteristic of apoptosis.

BDP inhibits the chaperone function of Hsp90 and downregulates the Hsp90 client proteins through the proteasomal pathway. To determine whether the observed anti-proliferative effect of BDP was associated with Hsp90 inhibition, we next evaluated the dose-dependent effect of BDP on the cellular biomarkers of Hsp90 inhibition. Since Hsp90 is responsible for maintaining the stability of EGFR, Her2, Met, Akt, c-Raf, and $\mathrm{Cdk} 4$, the inhibition of Hsp90 will induce the degradation of Hsp90 client proteins through the ubiquitin-proteasome pathway. As shown in Fig. 3A, the treatment of MDA-MB-231 cells with the indicated concentration of BDP for $24 \mathrm{~h}$ caused a dose-dependent decrease of EGFR, Her2, Met, Akt, c-Raf, and Cdk4. Interestingly, Her2 and Cdk4 more sensitively responded to the exposure of cells with BDP than other client proteins. The expression levels of Her2 and Cdk4 were almost completely depleted with $30 \mu \mathrm{M}$ of BDP. On the contrary, BDP upregulated the cellular protein level of Hsp70, the upregulation of which is considered a cellular hallmark of Hsp90 inhibition.

To further determine whether the observed downregulation of Hsp90 client proteins was a consequence of Hsp90-mediated proteasomal degradation, we performed a recovery experiment using a proteasomal inhibitor, MG-132 (Fig. 3B). BDP (30 $\mu \mathrm{M})$ significantly decreased the protein level of Met and Akt, whereas the pretreatment of MDA-MB-231 cells with $1 \mu \mathrm{M}$ of MG-132 recovered the protein abundance of these proteins.

We also investigated the dose-dependent effect of BDP on the transcriptional level of Met and Akt (Fig. 3C). As expected,
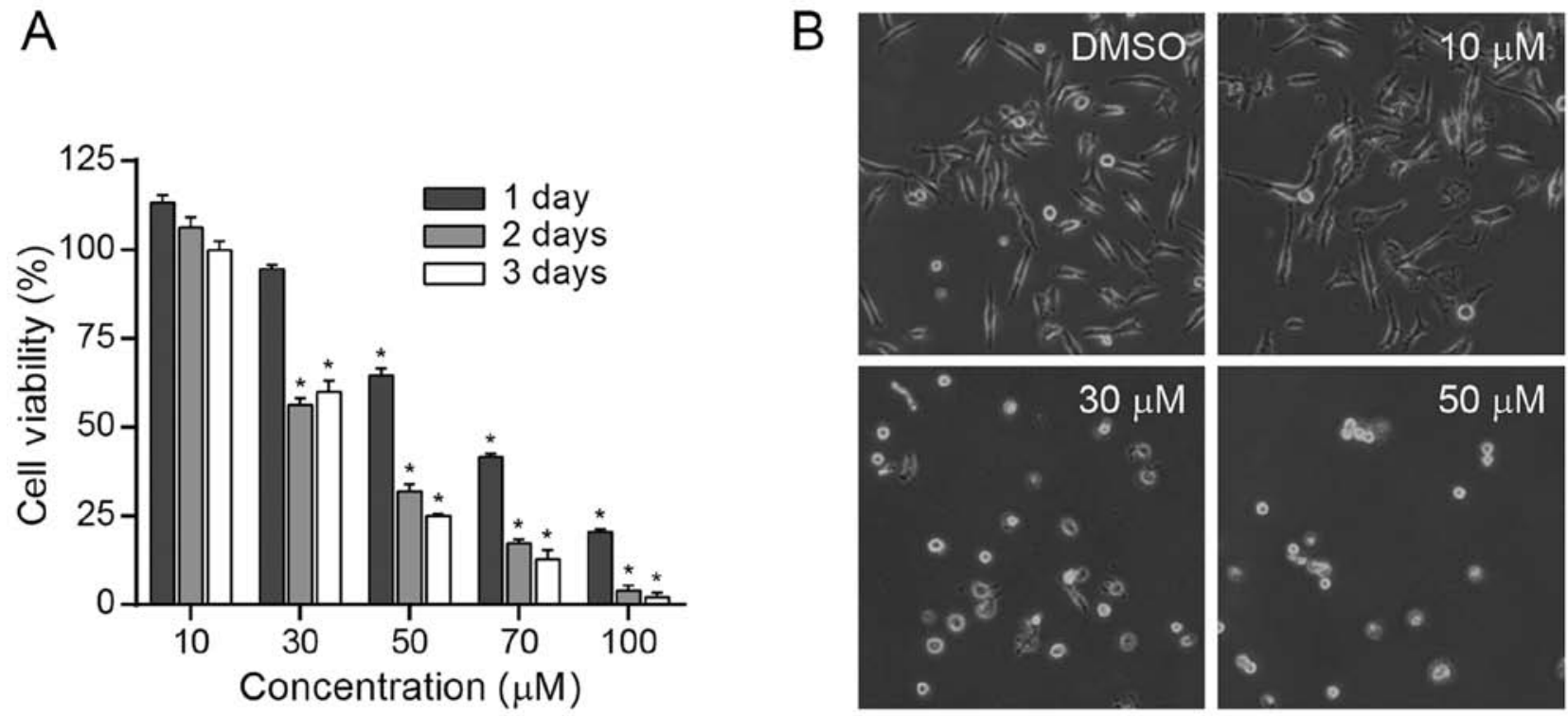

Figure 2. BDP inhibits the cell proliferation of triple-negative breast carcinoma MDA-MB-231 cells. (A) MDA-MB-231 cells were treated with the indicated concentration of BDP for 1, 2 and 3 days and cell viability was measured using MTS assay. Data are presented as mean \pm SD; ${ }^{*}$ p $<0.05$, significant difference compared with DMSO-treated control $(n=4)$. (B) MDA-MB-231 cells were treated with indicated concentration of BDP for $24 \mathrm{~h}$ and cell morphology was analyzed by a microscope. 

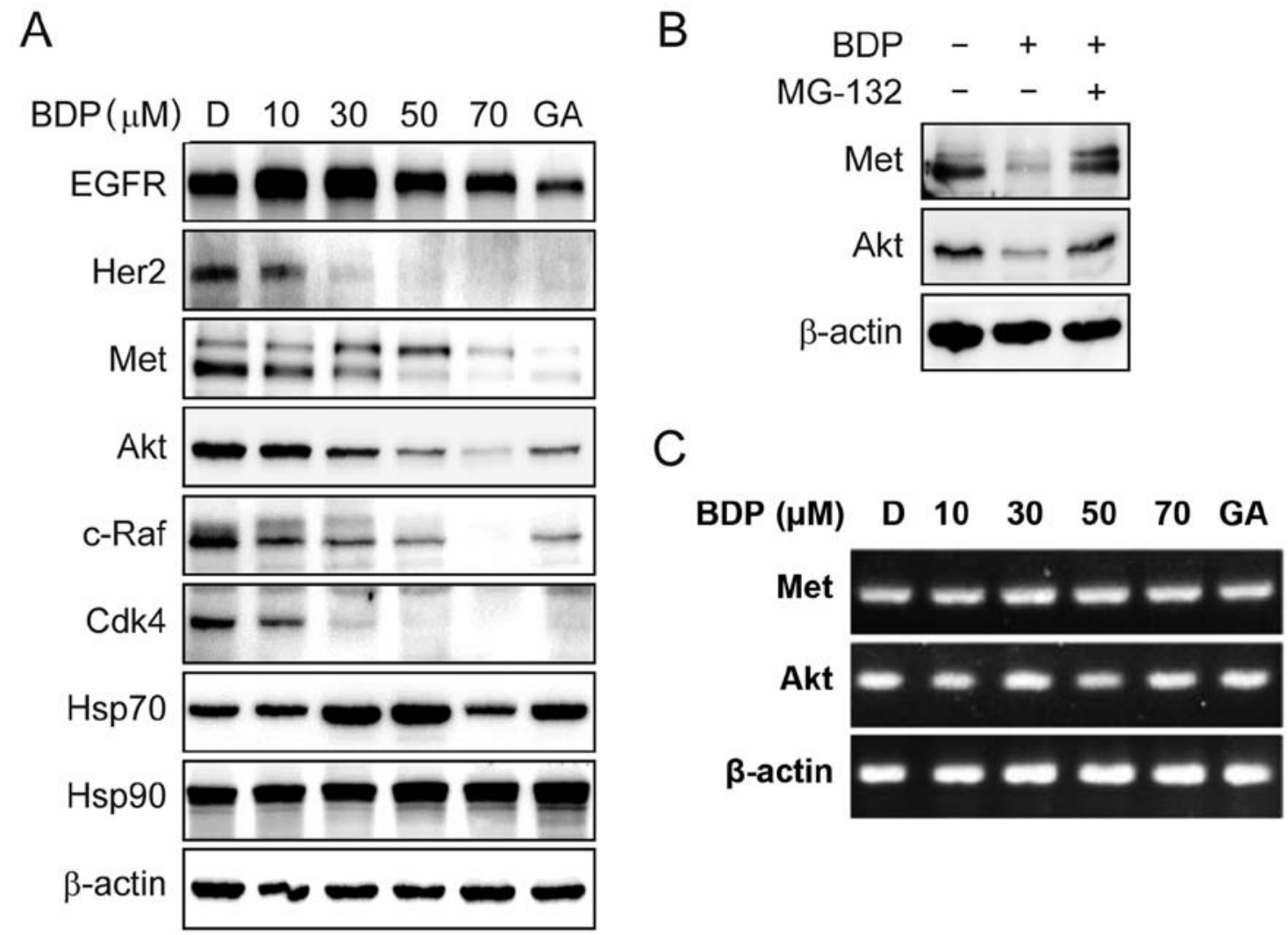

Figure 3. BDP induces the degradation of Hsp90 client proteins and the upregulation of Hsp70. (A) MDA-MB-231 cells were treated with the indicated concentration of BDP for $24 \mathrm{~h}$ and the expression of EGFR, Her2, Met, Akt, c-Raf, Cdk4, Hsp70, Hsp90, and $\beta$-actin was analyzed using western blotting. Geldanamycin (GA, $1 \mu \mathrm{M})$ and DMSO (D, 0.5\%) were employed as a positive and a negative control, respectively. (B) MDA-MB-231 cells were pretreated with $1 \mu \mathrm{M}$ of MG-132 for $3 \mathrm{~h}$ and then incubated with $30 \mu \mathrm{M}$ of BDP for additional $24 \mathrm{~h}$. The expression of Met, Akt, and $\beta$-actin were analyzed using western blotting. (C) Effect of BDP on the transcriptional levels of Met and Akt were measured by semi-quantitative RT-PCR. MDA-MB-231 cells were treated with indicated concentration of BDP or GA $(1 \mu \mathrm{M})$ for $24 \mathrm{~h}$. Total RNA was isolated from the cells, reverse transcribed to cDNA, and then assessed by semiquantitative RT-PCR.

BDP did not affect the transcriptional levels of Met and Akt, suggesting the downregulation of the Hsp90 client proteins, Met and Akt was not associated with the transcriptional regulation, but the proteasomal degradation.

Collectively, this result clearly suggested that BDP inhibited the chaperone function of Hsp90 and downregulated the Hsp90 client proteins via Hsp90-mediated proteasomal degradation pathway.

$B D P$ induces apoptotic cell death in MDA-MB-231 breast cancer cells. To address the question of whether the antiproliferative effect of BDP was associated with the induction of apoptotic cell death, MDA-MB-231 cells were treated with the indicated concentration of BDP for $24 \mathrm{~h}$, stained with Annexin $\mathrm{V}$ and propidium iodide, and then analyzed by fluorescenceactivated cell sorting (FACS). As shown in Fig. 4A and B, the exposure of MDA-MB-231 cells with BDP induced the early and late apoptosis in a dose-dependent manner.

The activation of caspases is an important indicator of apoptosis, which is stimulated by various apoptotic stimuli. To elucidate the mechanism of BDP-induced apoptotic cell death in MDA-MB-231 cells, we next examined the cellular levels of apoptotic biomarker proteins including poly(ADP-ribose) polymerase (PARP), cleaved PARP, caspase 3, cleaved caspase 3 , cleaved caspase 8 , B-cell lymphoma 2 (Bcl-2), and $\mathrm{Bcl}-2$ associated $\mathrm{X}$ protein (Bax), shown in Fig. 3C. Upon the exposure to BDP, the cleavage of PARP, caspase 3 , and caspase 8 were remarkably induced and the anti-apoptotic protein, Bcl-2 was significantly decreased in a dose-dependent manner, while the pro-apoptotic protein, Bax was unchanged. The result clearly suggested that BDP efficiently inhibited the growth of MDA-MB-231 cells through inducing apoptosis.

$B D P$ induces cell cycle arrest at the $G_{2} / M$ phases in $M D A-M B-231$ cells. To determine whether BDP affected the cell cycle, we analyzed the cell cycle distribution using flow cytometry. After exposure to the indicated concentration of BDP for $24 \mathrm{~h}$, the cell cycle distribution of MDA-MB-231 cells was analyzed. As shown in Fig. 5, the treatment of cells with BDP remarkably induced the cell cycle arrest at the $\mathrm{G}_{2} / \mathrm{M}$ phases compared to the DMSO control. Twenty-four-hour exposure to $10 \mu \mathrm{M}$ BDP increased the $\mathrm{G}_{2} / \mathrm{M}$ fraction from 21.3 to $30.1 \%$ and this increase was more marked when exposed to $30 \mu \mathrm{M} \mathrm{BDP}\left(\mathrm{G}_{2} / \mathrm{M}\right.$ fraction, $\left.47.9 \%\right)$. Similar results were also observed when exposed to $50 \mu \mathrm{M}$ BDP $\left(\mathrm{G}_{2} / \mathrm{M}\right.$ fraction, $\left.43.1 \%\right)$ or $70 \mu \mathrm{M}$ BDP $\left(\mathrm{G}_{2} / \mathrm{M}\right.$ fraction, 46.2\%). Consequently, the treatment of cells with BDP results in a reduction of the cell population at the $G_{0} / G_{1}$ phases, while the cell population at the $\mathrm{S}$ phase was not significantly 
A

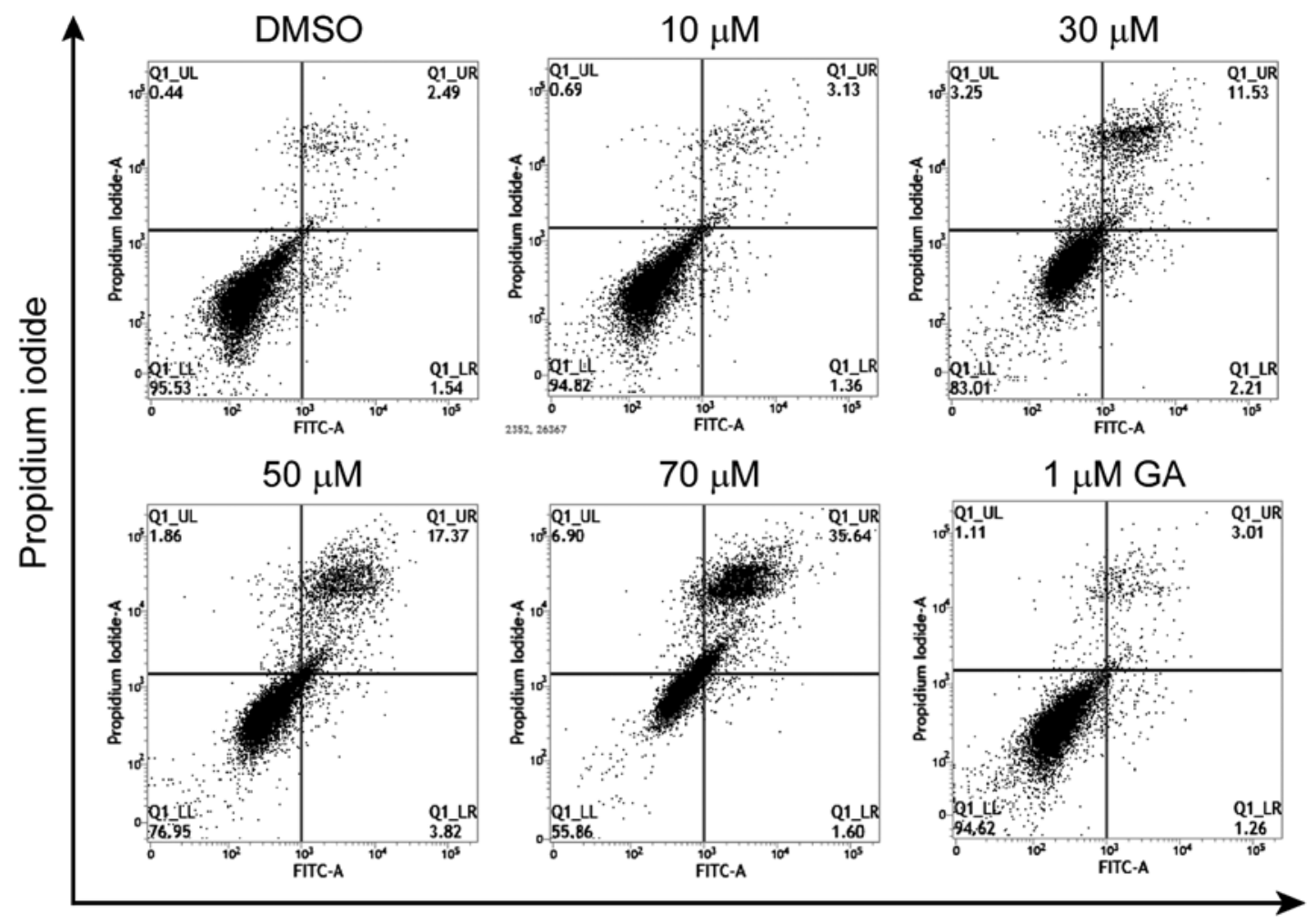

Annexin V-FITC
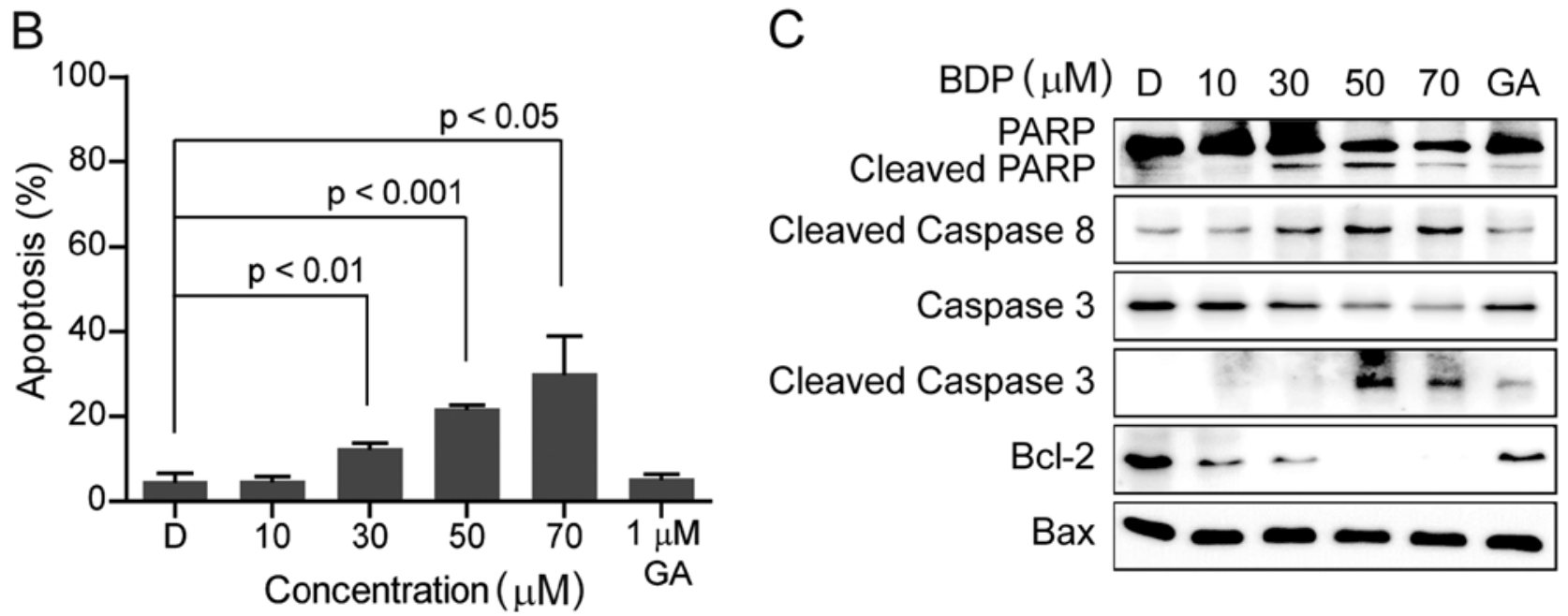

Figure 4. BDP induces apoptosis in MDA-MB-231 cells. (A) MDA-MB-231 cells were treated with the indicated concentration of BDP for $24 \mathrm{~h}$, and cells were then analyzed by flow cytometric analysis with Annexin V and propidium iodide staining. (B) Bar graphs represent the percentage of apoptotic MDA-MB-231 cells from three independent experiments by FACS analysis. Values are presented as mean \pm SD ( $n=3)$. (C) MDA-MB-231 cells were incubated with the indicated concentration of BDP for $24 \mathrm{~h}$ and the expression of the apoptotic marker proteins (PARP, caspase 8, caspase 3, Bcl-2, and Bax) was analyzed using western blotting. Geldanamycin $(\mathrm{GA}, 1 \mu \mathrm{M})$ and DMSO (D, 0.5\%) were employed as a positive and a negative control, respectively.

altered. Taken together, these findings revealed that BDP significantly induced cell cycle arrest at the $\mathrm{G}_{2} / \mathrm{M}$ phases in MDA-MB-231 cells.

$B D P$ impairs the migration of MDA-MB-231 cells. An increase of mobility has been associated with the metastatic potential of cancer cells. We thus evaluated the impact of BDP on the mobility of MDA-MB-231 cells. Wounds were formed by scratching the cell monolayer with a pipette tip and wound closure of MDA-MB-231 monolayer in the presence or absence of $10 \mu \mathrm{M}$ BDP was measured by counting the number of cells that had infiltrated the wounded area at $24 \mathrm{~h}$. As shown in Fig. 6A and B, the treatment of cells with $10 \mu \mathrm{M}$ BDP for $24 \mathrm{~h}$ suppressed the migration of MDA-MB-231 cells, in that the number of migrated cells was significantly decreased $(\mathrm{p}<0.01)$ in the BDP-treated group, 

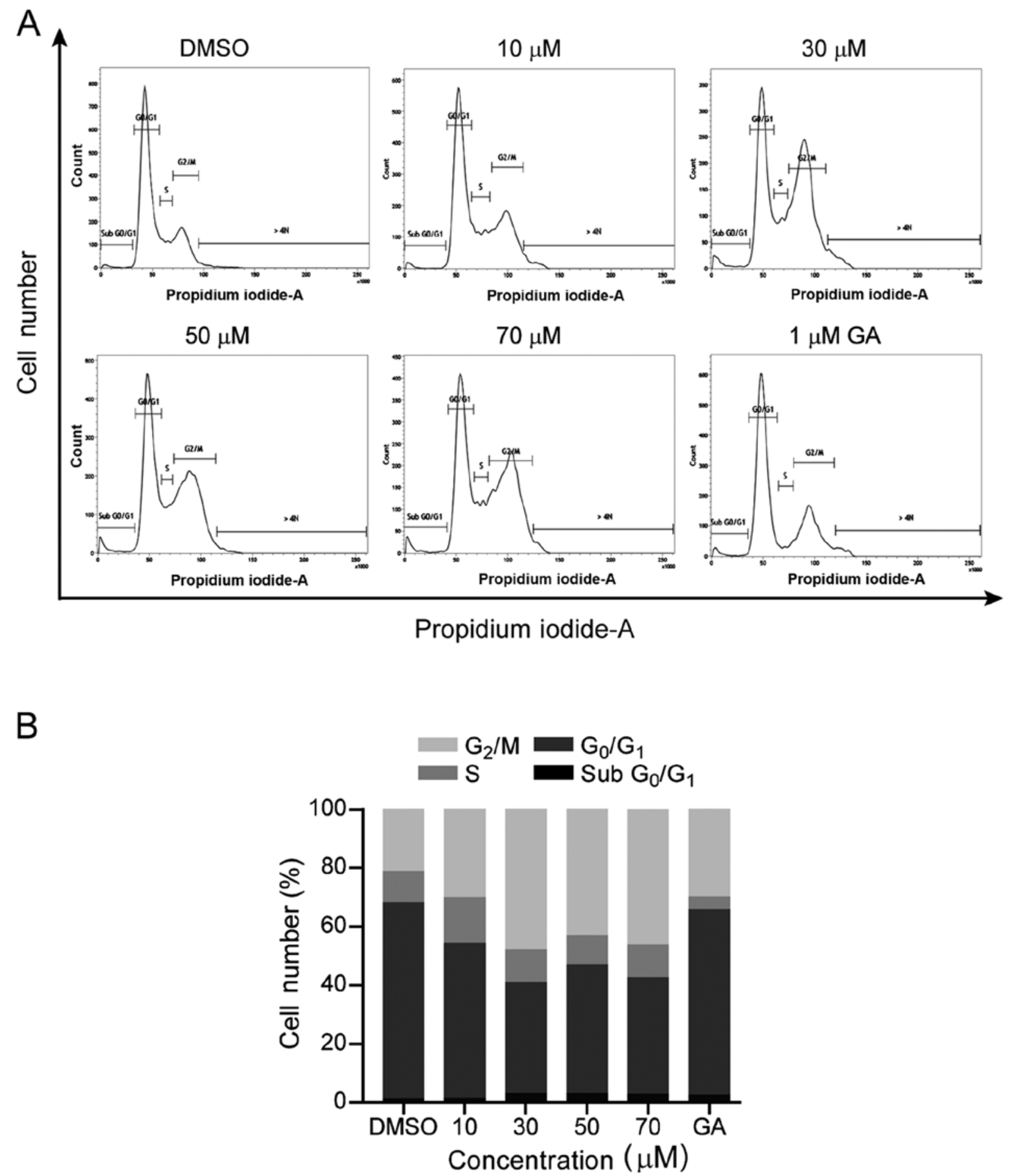

Figure 5. Effect of BDP on the cell cycle distribution in MDA-MB-231 cells. (A) After being treated with the indicated concentration of BDP or GA ( $1 \mu \mathrm{M})$ for $24 \mathrm{~h}$, MDA-MB-231 cells were collected, fixed, stained with propidium iodide, and analyzed by flow cytometry. The values represent the numbers of cells in the indicated phases of the cell cycle. (B) Stacked bar graphs represent percentage of cells in each cell cycle phase.

compared to the non-treated group without impacting cell viability (Fig. 6C). The assay indicated that BDP inhibited the migration of MDA-MB-231 cells.

$B D P$ inhibits the activity of MMP-9 in MDA-MB-231 cells. Gelatinases, such as MMP-2 and MMP-9, play a critical role in regulating extracellular matrix degradation. One of the gelatinases, MMP-9 is secreted by various types of malignant cells and contributes to tumor metastasis by breaking down various extracellular matrix molecules, which allows metastatic cells to be more invasive. In order to investigate the effect of BDP on MMP-9 activity, we performed gelatin zymography. As shown in Fig. 7A and B, BDP efficiently inhibited MMP-9 activity in MDA-MB-231 cells, compared to the DMSO control. BDP $(30 \mu \mathrm{M})$ significantly decreased the activity of MMP-9 to $21.3 \%(\mathrm{p}<0.01)$. The result clearly indicated that BDP inhibited the activity of MMP-9 in MDA-MB-231 cells. 
A

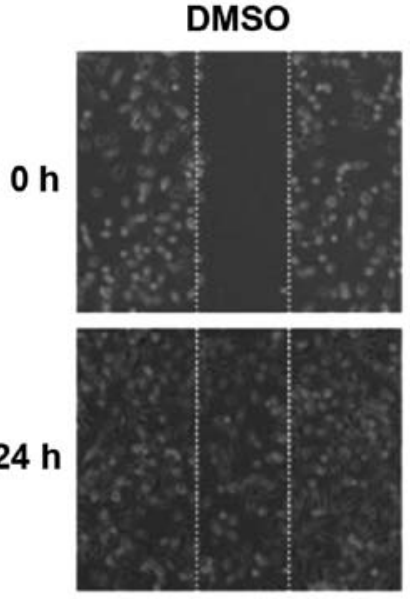

B

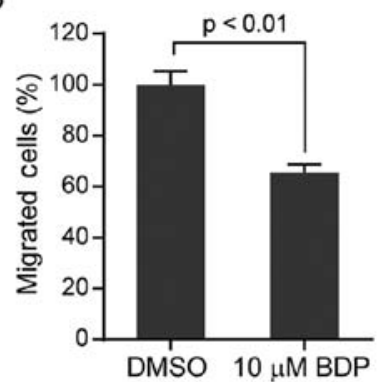

$10 \mu \mathrm{M}$ BDP

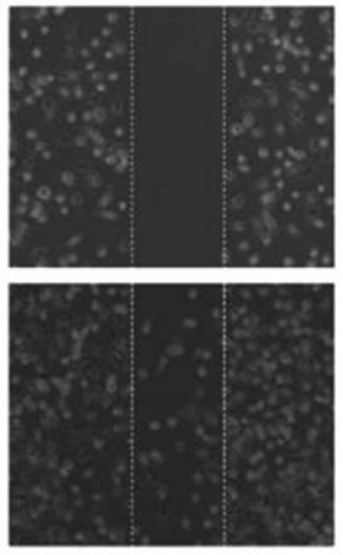

C

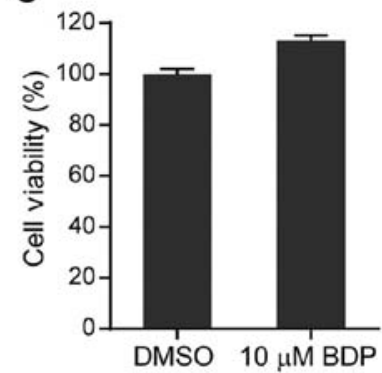

Figure 6. Effect of BDP on the migration of MDA-MB-231 cells. (A) Scratch wound healing assay was performed to examine the effect of BDP on the migration of MDA-MB-231 cells, 80-90\% confluent monolayers of MDA-MB-231 cells were scratched, and then incubated with DMSO or $10 \mu \mathrm{M}$ of BDP for $24 \mathrm{~h}$. Images of wounded monolayers were taken at $0 \mathrm{~h}$ and $24 \mathrm{~h}$. (B) Migration was measured by counting cell numbers within the wounded region. (C) MDA-MB-231 cells were incubated with the indicated concentration of BDP for $24 \mathrm{~h}$ and cell viability was measured using MTS assay. Data are presented as mean $\pm \operatorname{SD}(n=4)$.

\section{Discussion}

TNBC exhibits an aggressive subtype and a poor prognosis because these cancers lack ER, PR and Her2 receptors (27-29). Therefore, TNBC does not respond to hormone therapies or Her2 targeted therapies, which makes it difficult to treat TNBC (30). The molecular chaperone protein Hsp90 is widely expressed in breast cancers and plays a key role in regulating the stability and functions of many oncogenic proteins (31). Therefore, Hsp90 inhibition represents a promising anticancer strategy to treat TNBCs.

In this study, we investigated the biological activity of a chalcone-based small molecule, BDP and found that BDP efficiently impaired the growth of MDA-MB-231 breast cancer cells. Our data indicated that BDP treatment of MDA-MB-231 cells significantly led to the degradation of Hsp90 client proteins such as EGFR, Her2, Met, Akt, c-Raf, and Cdk4, while BDP upregulated Hsp70, which is a cellular hallmark of Hsp90 inhibition $(32,33)$. The downregulation of Hsp90 client proteins, Met and Akt could be reversed by adding a proteasome inhibitor, MG-132 indicating that BDP caused the degradation of Hsp90 client proteins by ubiquitin-proteasome pathway. The investigation of the transcription level demonstrated that BDP did not alter mRNA level of Met and Akt, further suggesting that the downregulation of the Hsp90 client
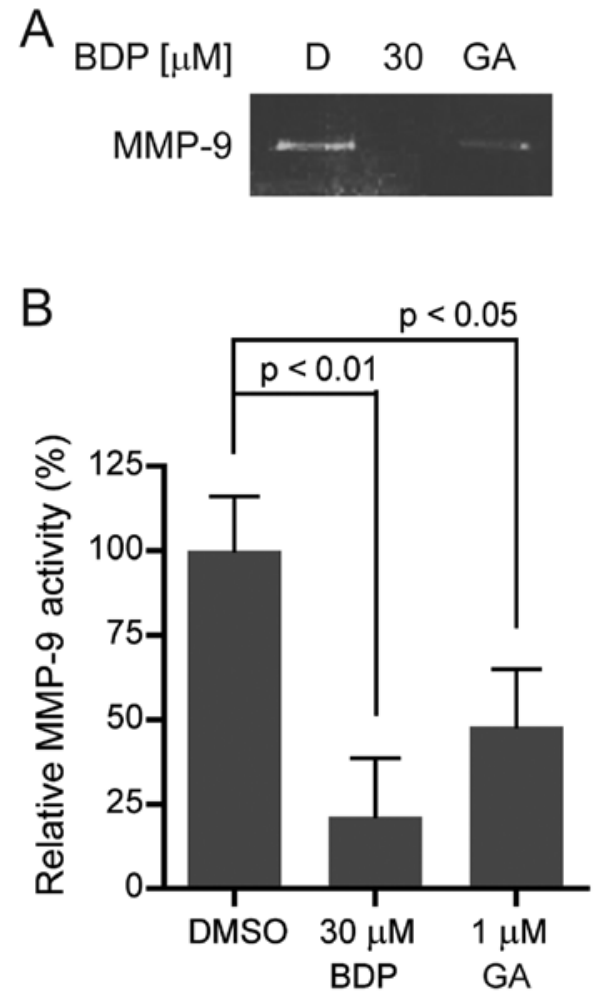

Figure 7. BDP inhibits MMP-9 activity in MDA-MB-231 cells. (A) MDA-MB-231 cells were incubated with the indicated concentration of BDP for $24 \mathrm{~h}$ and proteolytic activity of MMP-9 was measured by gelatin zymography assay. (B) Bar graphs represent relative MMP-9 activity. Data are presented as mean $\pm S D(n=3)$.

proteins, Met and Akt was not associated with the transcriptional regulation, but the proteasomal degradation.

Apoptosis is a tightly regulated cell suicide program that plays an essential role in maintaining the physiological balance between life and death of cells $(34,35)$. Accordingly, the proliferation of cancer can be suppressed by triggering apoptotic signaling pathways. As expected, BDP treatment of MDA-MB-231 cells induced the cleavage of PARP, caspase 3, and caspase 8 , while the anti-apoptotic protein, Bcl-2 was significantly downregulated in a dose-dependent manner. The result clearly suggested that BDP efficiently induced the apoptosis of MDA-MB-231 cells. BDP also caused cell cycle arrest in $\mathrm{G}_{2} / \mathrm{M}$ phase in MDA-MB-231 cells. As the percentage of cells in $\mathrm{G}_{2} / \mathrm{M}$ phase increased, the percentage of cells in $\mathrm{G}_{0} / \mathrm{G}_{1}$ phase decreased.

An increase of mobility has been associated with the metastatic potential of cancer cells and patients with TNBC have a tendency to metastasize to bone, lung, liver, and brain, which contributes to the poor prognosis with short overall survival $(36,37)$. In particular, MMPs are associated with cancer invasion and metastasis. Scratch wound healing assay and gelatin zymography assay demonstrated that BDP significantly abrogated the migratory and invasive capacity of MDA-MB-231 cells.

In conclusion, BDP suppressed the proliferation of triple-negative MDA-MB-231 breast cancer cells by inducing apoptosis, coupled with augmented $\mathrm{G}_{2} / \mathrm{M}$ phase arrest. Moreover, BDP displayed significant degradation of Hsp90 client proteins, including EGFR, Her2, Met, Akt, c-Raf, and 
Cdk4, and the upregulation of Hsp70. Our data also indicated the treatment with BDP attenuated the migratory and invasive capacity of MDA-MB-231 cells. Overall, these findings strongly supported that BDP could serve as a potential drug candidate to treat TNBC.

\section{Acknowledgements}

This study was supported by Basic Science Research Program throughtheNationalResearchFoundation of Korea(NRF)funded by the Ministry of Education (NRF-2016R1A6A1A03011325 and 2016R1D1A1B01009559), and Korea Institute of Planning and Evaluation for Technology in Food, Agriculture, Forestry and Fisheries (IPET) through Animal Disease Management Technology Development Program, funded by Ministry of Agriculture, Food and Rural Affairs (MAFRA) (116102-03).

\section{References}

1. Anders $\mathrm{C}$ and Carey LA: Understanding and treating triplenegative breast cancer. Oncology (Williston Park) 22: 1233-1239; discussion 1239-1240, 1243, 2008.

2. Osborne CK and Schiff R: Mechanisms of endocrine resistance in breast cancer. Annu Rev Med 62: 233-247, 2011.

3. Baselga J: Targeting the phosphoinositide-3 (PI3) kinase pathway in breast cancer. Oncologist 16 (Suppl 1): 12-19, 2011.

4. Gradishar WJ, Anderson BO, Balassanian R, Blair SL, Burstein HJ, Cyr A, Elias AD, Farrar WB, Forero A, Giordano SH, et al: NCCN Guidelines Insights Breast Cancer, Version 1.2016. J Natl Compr Canc Netw 13: 1475-1485, 2015.

5. Haffty BG, Yang Q, Reiss M, Kearney T, Higgins SA, Weidhaas J, Harris L, Hait W and Toppmeyer D: Locoregional relapse and distant metastasis in conservatively managed triple negative early-stage breast cancer. J Clin Oncol 24: 5652-5657, 2006.

6. Cheng Q, Chang JT, Geradts J, Neckers LM, Haystead T, Spector NL and Lyerly HK: Amplification and high-level expression of heat shock protein 90 marks aggressive phenotypes of human epidermal growth factor receptor 2 negative breast cancer. Breast Cancer Res 14: R62, 2012.

7. Dent R, Trudeau M, Pritchard KI, Hanna WM, Kahn HK, Sawka CA, Lickley LA, Rawlinson E, Sun P and Narod SA: Triple-negative breast cancer: Clinical features and patterns of recurrence. Clin Cancer Res 13: 4429-4434, 2007.

8. Sankhala KK, Mita MM, Mita AC and Takimoto CH: Heat shock proteins: A potential anticancer target. Curr Drug Targets 12: 2001-2008, 2011.

9. Bishop SC, Burlison JA and Blagg BS: Hsp90: A novel target for the disruption of multiple signaling cascades. Curr Cancer Drug Targets 7: 369-388, 2007.

10. Zuehlke A and Johnson JL: Hsp90 and co-chaperones twist the functions of diverse client proteins. Biopolymers 93: 211-217, 2010.

11. Mahalingam D, Swords R, Carew JS, Nawrocki ST, Bhalla K and Giles FJ: Targeting HSP90 for cancer therapy. Br J Cancer 100: 1523-1529, 2009.

12. Hanahan D and Weinberg RA: The hallmarks of cancer. Cell 100: 57-70, 2000.

13. Hanahan D and Weinberg RA: Hallmarks of cancer: The next generation. Cell 144: 646-674, 2011.

14. Normant E, Paez G, West KA, Lim AR, Slocum KL, Tunkey C, McDougall J, Wylie AA, Robison K, Caliri K, et al: The Hsp90 inhibitor IPI-504 rapidly lowers EML4-ALK levels and induces tumor regression in ALK-driven NSCLC models. Oncogene 30: 2581-2586, 2011.

15. Mishra L, Sinha R, Itokawa H, Bastow KF, Tachibana Y, Nakanishi Y, Kilgore N and Lee KH: Anti-HIV and cytotoxic activities of $\mathrm{Ru}(\mathrm{II}) / \mathrm{Ru}(\mathrm{III})$ polypyridyl complexes containing 2,6-(2'-benzimidazolyl)-pyridine/chalcone as co-ligand. Bioorg Med Chem 9: 1667-1671, 2001.
16. Chen M, Brøgger Christensen S, Zhai L, Rasmussen MH, Theander TG, Frøkjaer S, Steffansen B, Davidsen J and Kharazmi A: The novel oxygenated chalcone, 2,4-dimethoxy4'-butoxychalcone, exhibits potent activity against human malaria parasite Plasmodium falciparum in vitro and rodent parasites Plasmodium berghei and Plasmodium yoelii in vivo. J Infect Dis 176: 1327-1333, 1997.

17. Ducki S: The development of chalcones as promising anticancer agents. IDrugs 10: 42-46, 2007.

18. Chua AW, Hay HS, Rajendran P, Shanmugam MK, Li F, Bist P, Koay ES, Lim LH, Kumar AP and Sethi G: Butein downregulates chemokine receptor CXCR4 expression and function through suppression of NF- $x \mathrm{~B}$ activation in breast and pancreatic tumor cells. Biochem Pharmacol 80: 1553-1562, 2010.

19. Katsori AM and Hadjipavlou-Litina D: Chalcones in cancer: Understanding their role in terms of QSAR. Curr Med Chem 16: 1062-1081, 2009.

20. Liu X and Go ML: Antiproliferative properties of piperidinylchalcones. Bioorg Med Chem 14: 153-163, 2006.

21. Modzelewska A, Pettit C, Achanta G, Davidson NE, Huang P and Khan SR: Anticancer activities of novel chalcone and bischalcone derivatives. Bioorg Med Chem 14: 3491-3495, 2006.

22. Jeong JH, Oh YJ, Kwon TK and Seo YH: Chalcone-templated Hsp90 inhibitors and their effects on gefitinib resistance in non-small cell lung cancer (NSCLC). Arch Pharm Res 40: 96-105, 2017.

23. Jeong JH, Oh YJ, Lho Y, Park SY, Liu KH, Ha E and Seo YH: Targeting the entry region of Hsp90's ATP binding pocket with a novel 6,7-dihydrothieno[3,2-c]pyridin-5(4H)-yl amide. Eur J Med Chem 124: 1069-1080, 2016.

24. Jeong CH, Park HB, Jang WJ, Jung SH and Seo YH: Discovery of hybrid Hsp90 inhibitors and their anti-neoplastic effects against gefitinib-resistant non-small cell lung cancer (NSCLC). Bioorg Med Chem Lett 24: 224-227, 2014.

25. Lee T and Seo YH: Targeting the hydrophobic region of Hsp90's ATP binding pocket with novel 1,3,5-triazines. Bioorg Med Chem Lett 23: 6427-6431, 2013.

26. Seo YH and Jeong JH: Synthesis of butein analogues and their anti-proliferative activity against gefitinib-resistant non-small cell lung cancer (NSCLC) through Hsp90 inhibition. Bull Korean Chem Soc 35: 1294-1298, 2014.

27. Chacón RD and Costanzo MV: Triple-negative breast cancer. Breast Cancer Res 12 (Suppl 2): S3, 2010.

28. Elias AD: Triple-negative breast cancer: A short review. Am J Clin Oncol 33: 637-645, 2010.

29. Hudis CA and Gianni L: Triple-negative breast cancer: An unmet medical need. Oncologist 16 (Suppl 1): 1-11, 2011.

30. Andreopoulou E, Schweber SJ, Sparano JA and McDaid HM: Therapies for triple negative breast cancer. Expert Opin Pharmacother 16: 983-998, 2015.

31. Sidera K and Patsavoudi E: Extracellular HSP90: Conquering the cell surface. Cell Cycle 7: 1564-1568, 2008.

32. Sekihara K, Harashima N, Tongu M, Tamaki Y, Uchida N, Inomata $T$ and Harada M: Pifithrin- $\mu$, an inhibitor of heat-shock protein 70, can increase the antitumor effects of hyperthermia against human prostate cancer cells. PLoS One 8: e78772, 2013.

33. Banerji U, O'Donnell A, Scurr M, Pacey S, Stapleton S, Asad Y, Simmons L, Maloney A, Raynaud F, Campbell M, et al: Phase I pharmacokinetic and pharmacodynamic study of 17-allylamino, 17-demethoxygeldanamycin in patients with advanced malignancies. J Clin Oncol 23: 4152-4161, 2005.

34. Viktorsson K, Lewensohn R and Zhivotovsky B: Apoptotic pathways and therapy resistance in human malignancies. Adv Cancer Res 94: 143-196, 2005.

35. Jiang X and Wang X: Cytochrome $C$-mediated apoptosis. Annu Rev Biochem 73: 87-106, 2004.

36. Tseng LM, Hsu NC, Chen SC, Lu YS, Lin CH, Chang DY, Li H, Lin YC, Chang HK, Chao TC, et al: Distant metastasis in triple-negative breast cancer. Neoplasma 60: 290-294, 2013.

37. Trinca $F$, Inacio $M$, Timoteo $T$ and Dinis R: Triple-negative breast cancer with brain metastasis in a pregnant woman. BMJ Case Rep 20172017. doi:10.1136/bcr-2016-218657. 